\title{
Effects of Rearing Period in Seawater on Induced Maturation in Female Japanese Eel Anguilla japonica
}

\author{
Hirohiko Kagawa, ${ }^{* 1, \dagger}$ Norio Iinuma, ${ }^{* 2}$ Hideki Tanaka, ${ }^{* 1}$ \\ Hiromi Ohta, ${ }^{* 1}$ and Koichi Okuzawa*3 \\ *1National Research Institute of Aquaculture, Nansei, Mie 516-0193, Japan \\ ${ }^{*}$ Faculty of Bioresources, Mie University, Kamihama, Tsu, Mie 514-8507, Japan \\ ${ }^{*}$ Inland Station, National Research Institute of Aquaculture, Tamaki, Mie 519-0423, Japan
}

(Received June 9, 1997)

\begin{abstract}
The effects of rearing period in seawater on induced maturation by hormonal treatments were examined in the cultured female Japanese eels Anguilla japonica. The oocytes of female eel (30 month old) kept in seawater for 3 months completed vitellogeneisis by significantly smaller number of injection of salmon pituitary extracts than those of female kept in seawater for one week. Fertility and hatching rates were not significantly different between the oocytes of the two experimental groups. Similar results were obtained in the experiment which was performed using 6-month older females. These results indicate that long term rearing in seawater increased responsiveness to salmon pituitary extract in ovarian maturation. Histological observation revealed that oocytes of females kept in seawater for 3 months became large and attained at the primary yolk globule stage, whereas oocytes of the females kept in seawater for one week were at the oil drop stage. Electron microscopic observation showed that gonadotrophs became active in the pituitary of females kept in seawater for 3 months. These results are the first findings showing that vitellogenesis is triggered under artificial rearing condition without any hormone treatments in cultured immature eels. These morphological results indicate that long term rearing in seawater induces vitellogneisis in the females, resulting in the shortened period for compeletion of vitellogeneisis by the injection of salmon pituitary extract.
\end{abstract}

Key words: female eel, Anguilla japonica, induced maturation, seawater rearing, vitellogenesis

The Japanese eel Anguilla japonica migrates to the sea from rivers or lakes during the period from fall to winter and is thought to spawn eggs in its spawning area (North Equatorial Current west of the Mariana Islands). ${ }^{1)} \mathrm{Fe}-$ males may become sexually mature during marine migration toward the spawning area. Therefore, environmental factors encountered during this migration might to be responsible for stimulating sexual maturation in the eel. There have been some evidences concerning the stimulatory effects of environmental factors on sexual maturation in the eel. For example, estradiol-17 $\beta$ levels in the plasma are higher in female European eel Anguilla anguilla kept in seawater than in females kept in freshwater, suggesting that salinity might be an external factor which stimulates the production of estradiol-17 $\beta .^{2)}$ Moreover, increasing levels of salinity accelerate testicular maturation induced by injection of human chorionic gonadotropin, and the maturity reached in shorten period in male European eel. ${ }^{3)}$ These results indicate that the salinity is one of essential stimulating factors for sexual maturation in the eel.

In our previous experiments, ${ }^{4-6)}$ we used cultured eels for induction of maturation by hormone treatment. The eels have immature oocytes at the oil drop stage in their ovaries at the initial stage of hormone treatment. However, migrating silver eels have more advanced-stage oocytes such as the yolk globule stage. ${ }^{7}$ This is an advantage for inducing sexual maturation in the silver eel, since the number of injections of salmon pituitary extract which accompanies a lot of labor can be reduced. Therefore, the present study examined the effects of rearing period in seawater on induced maturation in cultured eels. The effects of the rearing period on maturation were evaluated by examining the number of injections of salmon pituitary extract and the fertility and hatching rates of ovulated eggs. Morphological observation of the ovary and pituitary was also conducted to assess the effects of rearing period in the seawater.

\section{Materials and Methods}

Cultured eels which had been reared in fresh water pond for 30 months (Experiment 1) and for 36 months (Experiment 2) from the glass eels ${ }^{8)}$ were used in the present study. Mean body weight of two experiment groups were $727 \mathrm{~g}$ (ranging from $516 \mathrm{~g}$ to $1044 \mathrm{~g}$ ) and $802 \mathrm{~g}$ (ranging from $554 \mathrm{~g}$ to $1108 \mathrm{~g}$ ) in Experiment 1 and 2, respectively. For acclimation to seawater, they were kept without feeding in 1 or 5 metric ton tanks under a controlled photoperiod of $14 \mathrm{~L}-10 \mathrm{D}$ at a water temperature of $20^{\circ} \mathrm{C}$. They were immersed in freshwater which gradually increased the concentrations of seawater for over 4 days. All fish used in Experiment 1 were acclimatized to seawater on the same day and

\footnotetext{
${ }^{\dagger}$ Correspondence and reprint requests should be sent to H. Kagawa.
} 
were divided into 2 groups. Injection of salmon pituitary extracts was started 1 week or 3 months after acclimation to seawater, respectively. Experiment 1 was carried out from September 1996 to February 1997. In Experiment 2, fish were acclimatized to seawater as mentioned above and were divided into 2 groups. Each experimental group of fish was started to inject salmon pituitary extracts 1 or 3 months after acclimation to seawater, respectively. Experiment 2 was carried out from April to September 1996. Fish were kept in 1 metric ton flow-through seawater tanks under controlled photoperiod of 14L-10D at a water temperature of $20^{\circ} \mathrm{C}$. In the present study, we could not prepare the fish groups which were reared in the freshwater for 3 months as a control of fish group reared in seawater, since only limited number of fish could be used.

After rearing in seawater for respective periods, female eels were injected intraperitoneally with $0.2 \mathrm{~m} /$ of salmon pituitary extract ( $20 \mathrm{mg}$ pituitary powder/fish) once a week. ${ }^{5}$ Oocyte diameter and maturity stage were determined by taking oocytes through the genital pore with a polyethylene cannula from the ovary of fish whose body weight indices (body weight/ initial body weight $\times 100$ ) exceeded $105 \%$. Responsiveness to salmon pituitary extract was evaluated by the number of injections of the hormone until completion of vitellogenesis (oocytes become over $750 \mu \mathrm{m}$ in diameter). After completion of vitellogenesis, the final treatment was performed for inducing oocyte final maturation and ovulation.

The final treatment was as follows. Two days after the weekly injection, fish which possessed oocytes over $750 \mu \mathrm{m}$ in diameter at the migratory nucleus stage were processed according to the method described in the previous study. ${ }^{5,6)}$ Briefly, fish were injected with $0.2 \mathrm{ml}$ of salmon pituitary extract $(20 \mathrm{mg} / \mathrm{fish})$ as a priming dose at 18:00 followed $24 \mathrm{~h}$ later by injection of $17,20 \beta$-dihydroxy-4pregnen-3-one (DHP, $2 \mu \mathrm{g} / \mathrm{g}$ body weight) intraperitoneally at 18:00. DHP was dissolved with 50\% ethanol at a concentration of $2 \mu \mathrm{g} / \mu \mathrm{l}$. Ovulation was checked by applying gentle pressure on the abdomen every 3 hours, from 9:00 of the following day of the DHP injection. Fertility and hatching rates were examined in each ovulated females by the methods as described previously. ${ }^{5)}$ Briefly, $2 \mathrm{~g}$ of ovulated eggs were inseminated with $1 \mathrm{ml}$ of diluted semen. Approximately 100 eggs were incubated in a plastic Petri dish filled with $20 \mathrm{~m} l$ of filtered seawater at $23^{\circ} \mathrm{C}$. Mean fertility and hatching rates were estimated from 3 replicates. Comparison of the two means was made with the Student's $t$-test.

\section{Histological Observations}

To examine oocyte diameter and developmental stages of oocytes, females ( 6 fish in each experiment) were sampled on the day when the first injection of salmon pituitary extract was started. Fish were sacrificed by decapitation after being deeply anesthetized with 2-phenoxyethanol. After measuring body and gonad weight, gonadosomatic index (GSI) was calculated by gonad weight/body weight $\times 100$. Small pieces of ovary were fixed in Bouin's solution, embedded in paraffin, sectioned, and stained with hematoxylin and eosin to assess oocyte diameter and the developmental stages of the oocytes. The oocyte diameter of 30 oocytes at the most advanced stage was meas- ured on light microscopic photographs. The developmental stages of the oocytes were followed according to Yamamoto et al. ${ }^{\text {7) }}$ To examine the activity of gonadotrophs with an electron microscope, pituitaries were fixed in $2 \%$ paraformaldehyde- $2.5 \%$ glutaraldehyde in $0.1 \mathrm{M}$ cacodylate buffer ( $\mathrm{pH} \mathrm{7.4)}$ for $18 \mathrm{~h}$ at $4^{\circ} \mathrm{C}$ and postfixed in $1 \%$ osmium tetroxide in $0.1 \mathrm{M}$ cacodylate buffer for $2 \mathrm{~h}$ at $4^{\circ} \mathrm{C}$. After dehydration, the tissues were embedded in Epon. Ultrathin sections were cut on a SORVALL MT2-B ultramicrotome and viewed with a JEM-120 electron microscope after staining with uranyl acetate and lead nitrate.

\section{Results}

Number of Injections of Salmon Pituitary Extract Until Final Treatment

In Experiment 1 (Fig. 1), one of the females which had been reared in seawater for one week reached an adequate stage for the final treatment (oocyte diameter become over $750 \mu \mathrm{m}$ ) after 8 injections of salmon pituitary extract. Thereafter, four females received the final treatment after 9 injections. The number of females treated in the final treatment reached a maximum (8 females) in the week of the 10th injection and gradually decreased until the last fish received the final treatment in the week of the 15 th injection. In the second group which had been reared in seawater for 3 months, 4 females received the final treatment after the 7 th injection. Fifteen and 9 females received the final treatment after the 8th and 9th injection, respectively. Thereafter, 3 and 2 females received the final treatment after 10 and 11 injections, respectively. Mean number of injections of salmon pituitary extract was significantly $(p<0.01)$ smaller in the 3 -month group $(8.5 \pm 0.2 ; n=33)$ than in the 1 -week group $(10.6 \pm 0.4$; $\mathrm{n}=23$ ).

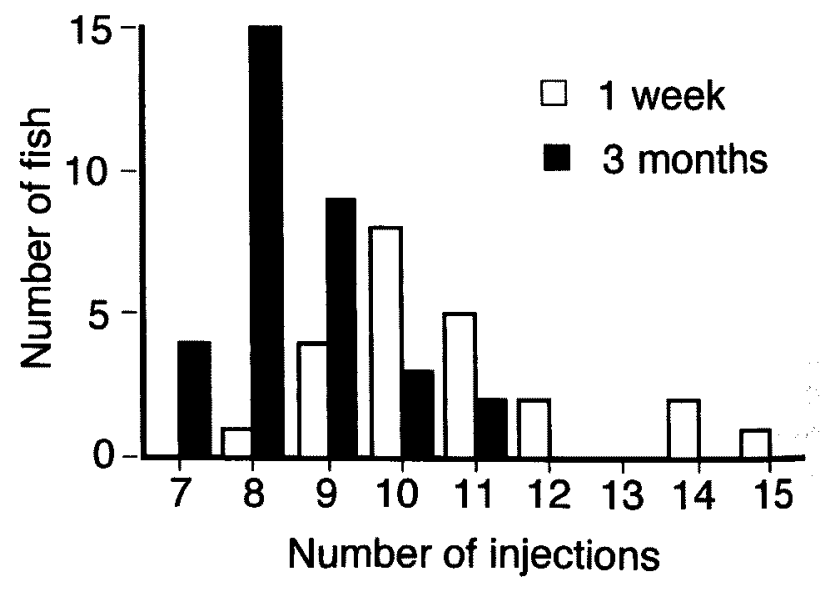

Fig. 1. Number of injections of salmon pituitary extract until the final treatment in Experiment 1.

Thirty month-old females were reared in seawater for 1 week and 3 months. Females of each group were injected with salmon pituitary extract $(20 \mathrm{mg} / \mathrm{fish})$ once a week. Females which possessed oocytes of over $750 \mu \mathrm{m}$ in diameter were processed with final treatments (salmon pituitary extracts followed $24 \mathrm{~h}$ later by injection of DHP, $2 \mu \mathrm{g} / \mathrm{g}$ body weight). Number of females processed with final treatment was counted every week. 


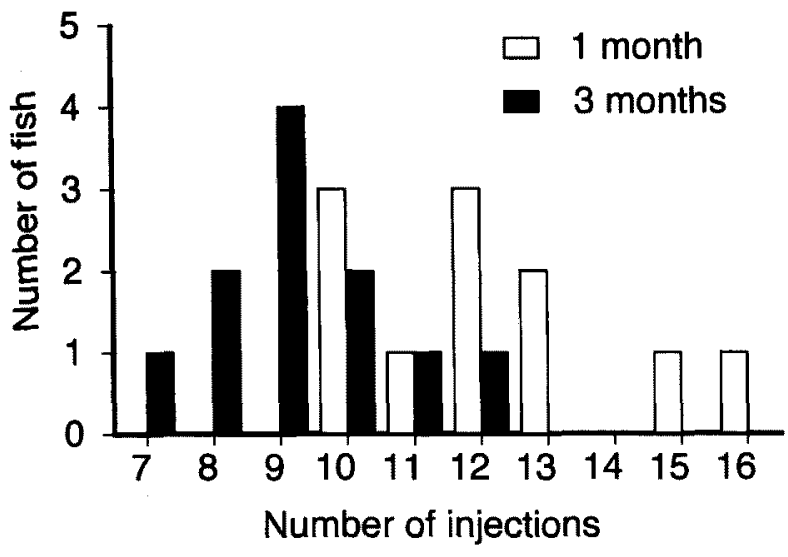

Fig. 2. Number of injections of salmon pituitary extract until the final treatments in Experiment 2.

Thirty six year-old females were reared in seawater for 1 and 3 months. Females of each group were injected with salmon pituitary extract $(20 \mathrm{mg} / \mathrm{fish})$ once a week. Females which possessed oocytes of over $750 \mu \mathrm{m}$ in diameter were processed with final treatments (salmon pituitary extracts followed $24 \mathrm{~h}$ later by injection of DHP, $2 \mu \mathrm{g} / \mathrm{g}$ body weight). Number of females processed with final treatments was counted every week.

In Experiment 2 (Fig. 2), 3 females which had been reared in seawater for one month reached an adequate stage for the final treatment after 10 injections. One and 3 females received the final treatment after 11 and 12 injections, respectively. After 13 injections, 2 females received the final treatment and thereafter each female received the final treatment after the 15 th and 16 th injection. In the second group which had been kept in seawater for 3 months, 1 female received the final treatment after 7 injections. Thereafter, the number of females which received the final treatment increased and reached a peak in the 9th injection. Two females received the final treatment after the 10 th injection and 1 female received the final treatment after the 11th and 12th injections. Mean number of injections of salmon pituitary extract was significantly $(p<0.01)$ smaller in the 3 -month group $(9.3 \pm 0.4 ; \mathrm{n}=11)$ than in the 1 -month group $(12.2 \pm 0.6 ; n=11)$.

\section{Ovulation Time}

In the 1-week group of Experiment 1 (Table 1), ovulation was observed in 6 of 23 females at 9:00 (15 h after DHP injection), in 14 females at 12:00 (18 h after DHP injection), and in 3 females at 15:00 (21 h after DHP injection). A similar pattern of ovulation was observed in females kept for 3 months; 9,15 , and 9 females ovulated at 9:00, 12:00, and 15:00, respectively. In the 1-month group of Experiment 2 (Table 2), 3, 5, and 1 females ovulated at 9:00, 12:00, and 15:00, respectively. In females kept for 3 months, ovulation was observed in 5,4 , and 2 females at 9:00, 12:00, and 15:00, respectively.

\section{Fertility and Hatching Rates}

In the 1-week group of Experiment 1 (Table 3), the fertility rates of fish which ovulated $15 \mathrm{~h}$ and $18 \mathrm{~h}$ after DHP injection were $70.3 \pm 13.0 \%$ and $40.8 \pm 7.7 \%$, respectively. Hatching rates at $15 \mathrm{~h}$ and $18 \mathrm{~h}$ after DHP injection were $60.2 \pm 11.8 \%$ and $23.1 \pm 5.1 \%$, respectively. Both fertility
Table 1. Ovulation time of eel reared in seawater for 1 week or 3 months

\begin{tabular}{lccc}
\hline $\begin{array}{c}\text { Rearing } \\
\text { period }\end{array}$ & $\begin{array}{c}\text { Ovulation time } \\
12: 00 \\
(15 \mathrm{~h})^{*_{1}}\end{array}$ & $\begin{array}{c}18 \mathrm{~h}) \\
15: 00 \\
(21 \mathrm{~h})\end{array}$ \\
\hline 1 week & $6^{*_{2}}$ & 14 & 3 \\
3 months & 9 & 15 & 9 \\
\hline
\end{tabular}

* Time after DHP injection.

*2 Number of fish ovulated.

Table 2. Ovulation time of eel reared in seawater for 1 or 3 months

\begin{tabular}{cccc}
\hline $\begin{array}{c}\text { Rearing } \\
\text { period }\end{array}$ & $\begin{array}{c}\text { Ovulation time } \\
12: 00 \\
(15 \mathrm{~h})^{* 1}\end{array}$ & $(18 \mathrm{~h})$ & $\begin{array}{c}15: 00 \\
(21 \mathrm{~h})\end{array}$ \\
\hline 1 month & $3^{*_{2}}$ & 5 & 1 \\
3 months & 5 & 4 & 2 \\
\hline
\end{tabular}

*1 Time after DHP injection.

$* 2$ Number of fish ovulated.

Table 3. Fertility and hatching rates of eel reared in seawater for 1 week

\begin{tabular}{lccc}
\hline $\begin{array}{c}\text { Ovulation time } \\
\text { (Time after } \\
\text { DHP injection) }\end{array}$ & $\begin{array}{c}9: 00 \\
(15 \mathrm{~h})\end{array}$ & $\begin{array}{c}12: 00 \\
(18 \mathrm{~h})\end{array}$ & $\begin{array}{c}15: 00 \\
(21 \mathrm{~h})\end{array}$ \\
\hline Fertility (\%) & $70.3 \pm 13.0^{* 1}$ & $40.8 \pm 7.7$ & $-{ }^{* 2}$ \\
Hatching rates (\%) & $60.2 \pm 11.8$ & $23.1 \pm 5.1$ & - \\
\hline
\end{tabular}

* Each value represents the mean \pm SEM.

*2 Fertilization tests were not examined.

and hatching rates were significantly $(p<0.01)$ higher in eggs ovulated at $15 \mathrm{~h}$ after DHP injection than in eggs ovulated at $18 \mathrm{~h}$ after DHP injection. Fertility and hatching rates of 3 females ovulated at 15:00 could not be examined. In the 3-month group of Experiment 1 (Table 4), the fertility rates of fish which ovulated $15 \mathrm{~h}, 18 \mathrm{~h}$, and $21 \mathrm{~h}$ after DHP injection were $65.1 \pm 9.9 \%, 57.5 \pm 8.3 \%$, and $13.9 \pm 7.9 \%$, respectively. Hatching rates at $15 \mathrm{~h}, 18 \mathrm{~h}$, and $21 \mathrm{~h}$ after injection were $58.0 \pm 9.4 \%, 39.1 \pm 7.2 \%$, and $1.0 \pm 0.6 \%$, respectively. Both fertility and hatching rates at $21 \mathrm{~h}$ after DHP injection were significantly $(p<0.01)$ lower than those at $15 \mathrm{~h}$ and $18 \mathrm{~h}$ after DHP injection. Total fertility and hatching rates in Experiment 1 are shown in Table 5 . There was no significant difference in fertility and hatching rates between the two groups reared in seawater for 1 week and 3 months. Total fertility and hatching rates of females reared for 1 month were $33.9 \pm 9.0 \%$ and $18.1 \pm 6.1 \%$, respectively (Table 6). Fertility and hatching rates of females kept in seawater for 3 months were $39.0 \pm 12.3 \%$ and $25.0 \pm 10.3 \%$, respectively. There was no significant difference in fertility and hatching rates between the two groups in Experiment 2 .

\section{GSI and Oocyte Diameter at the Initial Stage of Hormone Treatments}

In Experiment 1 (Fig. 3), GSI at the initial stage of hormone treatments of the 1 -week group was $0.9 \pm 0.1 \%$ and increased significantly $(p<0.01)$ to $1.6 \pm 0.1 \%$ in the females kept for 3 months. Oocyte diameters also significantly $(p<0.01)$ increased from $142.5 \pm 4.7 \mu \mathrm{m}$ in the 1 -week 
Table 4. Fertility and hatching rates of eel reared in seawater for 3 months

\begin{tabular}{lccc}
\hline \hline $\begin{array}{c}\text { Ovulation time } \\
\text { (Time after } \\
\text { DHP injection) }\end{array}$ & $\begin{array}{c}9: 00 \\
(15 \mathrm{~h})\end{array}$ & $\begin{array}{c}12: 00 \\
(18 \mathrm{~h})\end{array}$ & $\begin{array}{c}15: 00 \\
(2 \mathrm{~h})\end{array}$ \\
\hline Fertility (\%) & $65.1 \pm 9.9^{*}$ & $57.5 \pm 8.3$ & $13.9 \pm 7.9$ \\
Hatching rates (\%) & $58.0 \pm 9.4$ & $39.1 \pm 7.2$ & $1.0 \pm 0.6$ \\
\hline
\end{tabular}

* Each value represents the mean \pm SEM.

Table 5. Fertility and hatching rates of eel reared in seawater for 1 week or 3 months

\begin{tabular}{ccc}
\hline $\begin{array}{c}\text { Rearing } \\
\text { period }\end{array}$ & Fertility (\%) & Hatching rates $(\%)$ \\
\hline 1 week \\
$(\mathrm{n}=20)^{*_{2}}$ & $49.7 \pm 7.2^{*}$ & $34.2 \pm 6.2$ \\
3 months \\
$(\mathrm{n}=33)$ & $47.7 \pm 6.2$ & $33.9 \pm 5.6$ \\
\hline
\end{tabular}

$*_{1}$ Each value represents the mean \pm SEM.

*2 Number of fish examined.

Table 6. Fertility and hatching rates of eel reared in seawater for 1 or 3 months

\begin{tabular}{|c|c|c|}
\hline $\begin{array}{l}\text { Rearing } \\
\text { period }\end{array}$ & Fertility (\%) & Hatching rates (\%) \\
\hline $\begin{array}{l}1 \text { month } \\
(\mathrm{n}=9)^{* 2}\end{array}$ & $33.9 \pm 9.0^{* 1}$ & $18.1 \pm 6.1$ \\
\hline $\begin{array}{l}3 \text { months } \\
(n=11)\end{array}$ & $39.0 \pm 12.3$ & $25.0 \pm 10.3$ \\
\hline
\end{tabular}

*1 Each value represents the mean \pm SEM

*2 Number of fish examined.

group to $195.2 \pm 6.3 \mu \mathrm{m}$ in the 3-month group. In Experiment 2 (Fig. 4), GSI of the 1-month group was $1.0 \pm 0.1 \%$ and increased significantly $(p<0.05)$ to $1.4 \pm 0.2 \%$ in the 3-month group. Oocyte diameter increased significantly $(p<0.05)$ from $142.6 \pm 15.1 \mu \mathrm{m}$ in the 1 -month group to $168.9 \pm 20.2 \mu \mathrm{m}$ in the 3 -month group.

\section{Light Microscopic Observation}

Females kept for 1 week in Experiment 1 had oocytes at the oil drop stage in their ovaries (Fig. 5A). Three out of 6 females kept for 3 months had oocytes at the primary yolk globule stage in their ovaries (Fig. 5B, C); the remaining 3 females possessed oocytes at the oil drop stage. Females kept for 1 month or 3 months in Experiment 2 had oocytes at the oil drop stage (data not shown).

\section{Electron Microscopic Observation}

The gonadotrophs of the eels were identified by the morphological features as described in the previous papers. ${ }^{11}$ ) The gonadotrophs of the female eels which were reared in seawater for 1 week were very small in size and number (Fig. 6A). Their cytoplasm was very small in volume and their nucleus is located centrally. They contained only a few small secretory granules. The endoplasmic reticulum was observed around the nucleus. The Golgi apparatus was not well developed. In the eels kept for 3 months in seawater (Fig. 6B), a few gonadotrophs became large in

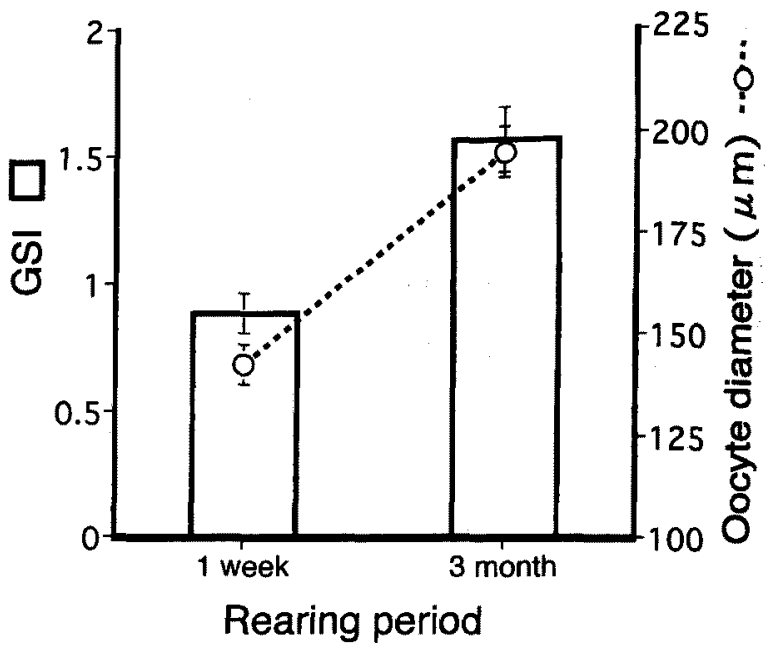

Fig. 3. Gonadosomatic indices (GSI) and oocyte diameter of females at initial stages of hormone treatment in Experiment 1.

GSI values (gonad weight/body weight $\times 100$ ) are represented by mean $\pm \mathrm{SEM}$ in 6 females in both experimental groups. Oocyte diameter is represented by mean \pm SEM of 30 oocytes at the most advanced stage.

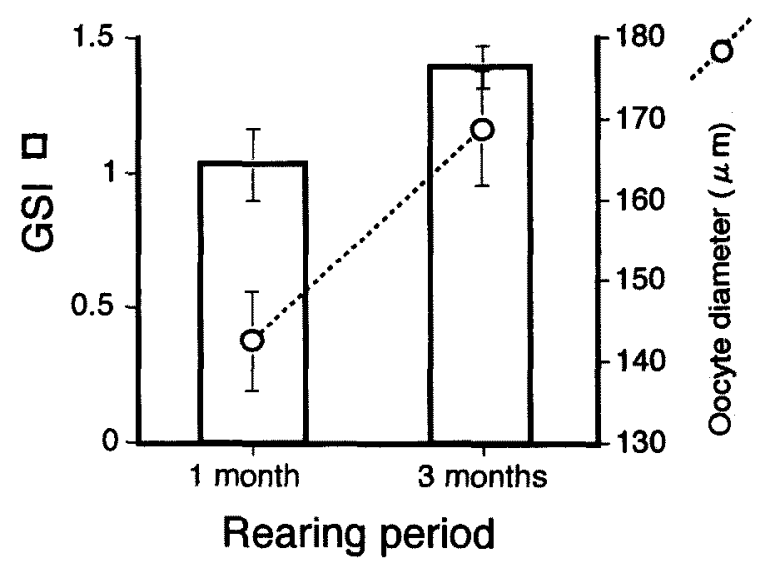

Fig. 4. Gonadosomatic indices (GSI) and oocyte diameter of females at initial stages of hormone treatment in Experiment 2.

GSI values (gonad weight/body weight $\times 100$ ) are represented by mean $\pm S E M$ in 6 females in both experimental groups. Oocyte diameter is represented by mean \pm SEM of 30 oocytes at the most advanced stage.

size and had a large cytoplasm. A relatively dilated rough endoplasmic reticulum appeared throughout the cytoplasm. Small electron dense granules increased in number in the cytoplasm. The Golgi apparatus was well developed. Similar morphological changes were observed in Experiment 2 .

\section{Discussion}

The present study showed that the mean number of injections of salmon pituitary extract until the final treatment was significantly less in the eels kept in seawater for 3 months than in the eels kept in seawater for 1 week (Expertment 1) or 1 month (Experiment 2). The number of injec- 

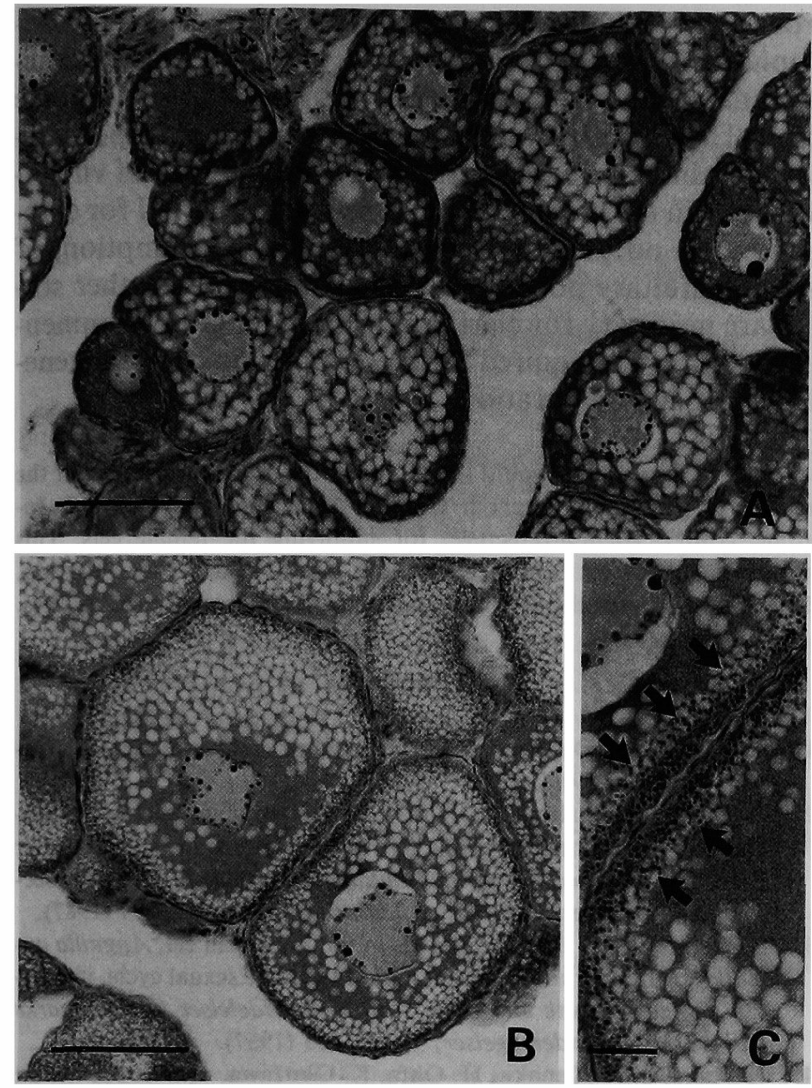

Fig. 5. Light micrographs of ovaries from females at initial stages of hormone treatment in Experiment 1.

Oocytes at the oil drop stage were observed in the ovaries of females kept for 1 week (A). Oocytes at the primary yolk globule stage were observed in the ovaries of females kept for 3 months (B). Yolk granules are present in the peripheral region of the oocytes $(C$, arrows). Bars indicate $100 \mu \mathrm{m}$ for $\mathrm{A}$ and $\mathrm{B}$ and $10 \mu \mathrm{m}$ for $\mathrm{C}$.

tions of salmon pituitary extract for maturation in the eels kept in seawater for 3 months $(8.5 \pm 0.2)$ was comparable to those in silver forms of females administrated with salmon pituitary extract (about $35 \mathrm{mg} /$ fish/week). ${ }^{9}$ These data indicate that a prolonged rearing period in seawater reduces the period needed until the final treatment. A shortened period for completion of oocyte growth reduces the consumption of salmon pituitary powder and labor required. We could not conclude whether 3 months are a minimum period needed for decreasing the period for completion of oocyte growth. More detailed experiments should be done in the future. The present study showed that the number of injections did not decrease in the females in Experiment 2 compared with those of the females in Experiment 1, even though the females used in Experiment 2 were 6 months older than the females in Experiment 1, suggesting that aging may not be an important factor for shortening the period for completion of yolk formation in the present study.

Most of the females ovulated $18 \mathrm{~h}$ after DHP injection (12:00 pm of the next day) in both experimental groups in Experiment 1 and 2. These observations confirmed the previous data showing that most of the females ovulate 18 $\mathrm{h}$ after DHP injection at 18:00. ${ }^{6)}$ Fertility and hatching
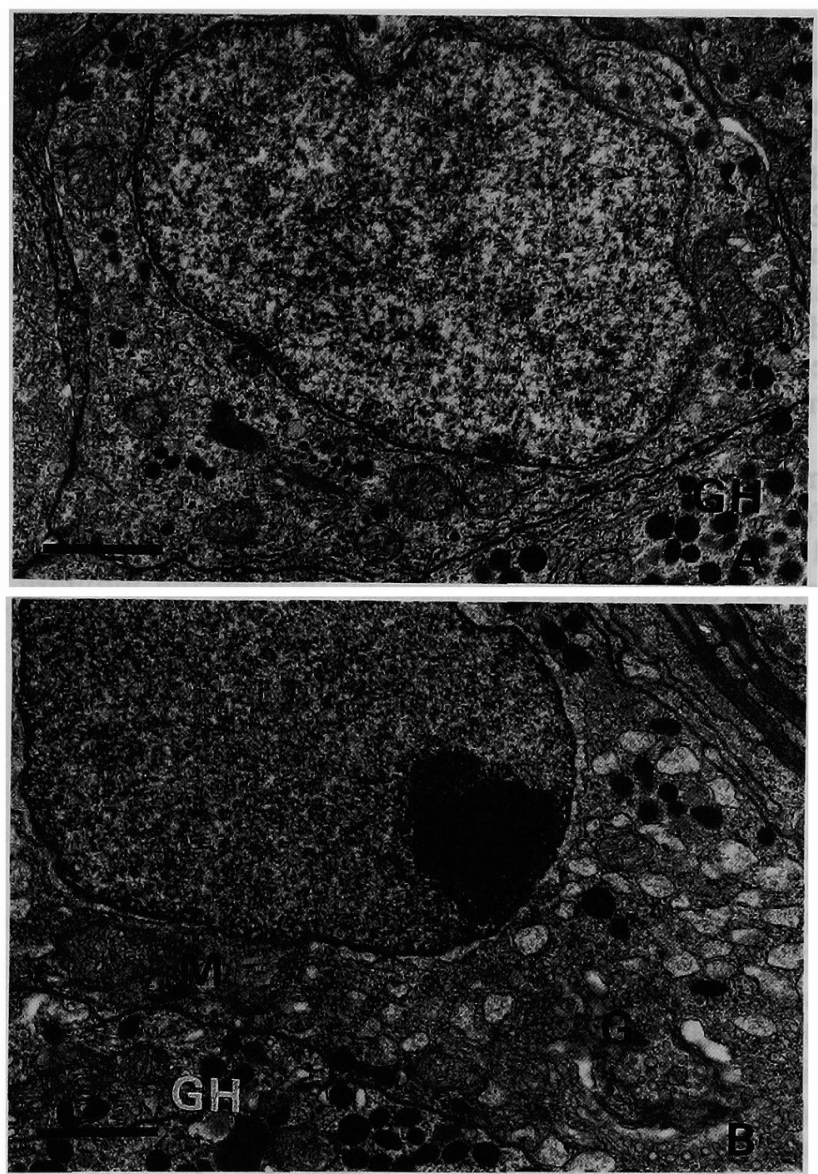

Fig. 6. Electron micrographs of gonadotrophs of females kept in seawater for 1 week (A) and 3 months (B).

Many electron dense granules and dilated rough endoplasmic reticulum are observed in the cytoplasm of gonadotrophs of the females kept for 3 months. G, Golgi apparatus; M, mitochondria; $\mathrm{GH}$, Somatotroph. Bars indicate $1 \mu \mathrm{m}$.

rates of fish ovulated $15 \mathrm{~h}$ after DHP injection were significantly higher than those of fish ovulated $18 \mathrm{~h}$ after DHP injection in the 1-week group of the Experiment 1. These results support the previous observations showing that fertility and hatching rates of females which ovulated in shorter latency first after DHP injection were much higher than those of other females. Similar patterns of fertility and hatching rates were observed in other experimental groups of the present study. The present study also showed that there was no significant difference in fertility and hatching rates between the two experimental groups in both Experiment 1 and 2. This indicates that egg quality is not affected by the long rearing period of 3 months. Thus, females can be kept in the seawater without feeding for at least 3 months as experimental fish.

Gonadosomatic index (GSI) and oocyte diameter increased during 3 months in the present study. GSI values were $1.4 \%$ and $1.6 \%$ in eels kept in seawater for 3 months in Experiment 1 and 2, respectively. These values are similar to those observed in the silver forms of wild female Japanese eels ${ }^{9)}$ and cultured female eels. ${ }^{10)}$ Mean oocyte diameter of fish kept in seawater for 3 months was 195 and $168 \mu \mathrm{m}$ in Experiment 1 and 2, respectively. In Experiment 
1, 3 females out of 6 had oocytes at the primary yolk globule stage in their ovaries. These histological observations are similar to those of the silver forms of wild female Japanese eels, showing that they have oocytes at the oil drop stage or at the primary yolk globule stage of about $200 \mu \mathrm{m}$ in diameter. ${ }^{7)}$ Thus, these results suggest that females reared in seawater for 3 months induces vitellogenesis similar to natural migrating females. This is the first evidence showing that vitellogenesis is induced in cultured eels reared under artificial conditions without any hormone treatment.

Gonadotrophs were very inactive in the pituitary of females kept for 1 week or 1 month. They became active in females kept in seawater for 3 months in both Experiment 1 and 2 , suggesting that rearing in seawater for a long period stimulates sexual maturity through the pituitarygonadal axis. A previous report ${ }^{11}$ described that gonadotrophs were not stimulated in male Japanese eels which were kept in seawater for 6 weeks. This may be caused by a shorter period of rearing in seawater than in the present experiment.

The present study shows that vitellogenic oocytes are observed in the ovary of fish kept in seawater for 3 months in Experiment 1, but not in fish with the same treatment in the Experiment 2 . In a previous study, seasonal changes in GSI values were reported in cultured eels kept in fresh water; GSI values increased from fall to winter. ${ }^{10)}$ It is thought from this data that female eels might be responsive to environmental factors even if they are kept in fresh water under natural conditions. Therefore, the responsiveness of the females of Experiment 1 to environmental factors might be higher than that of the females of Experiment 2 . From the data of the present study, we can not conclude what factors of the seawater treatment trigger puberty in cultured females. A previous study showed that plasma estradiol-17 $\beta$ became higher in the female European silver eel Anguilla anguilla when fish were transferred to seawater and kept for 2 months. ${ }^{2)}$ Moreover, the period needed for maturation decreases with an increase of salinity in the male European eels. ${ }^{3)}$ Thus, salinity might be an important external factor in the female eels used in the present study. However, Fontaine et al. ${ }^{12)}$ showed that gonadotropin and estradiol-17 $\beta$ in plasma increased when the fish were immersed in deep sea $(-450 \mathrm{~m}$ to $870 \mathrm{~m}$ in depth), suggesting that a high hydrostatic pressure, not salinity and not photoperiod, is important in triggering puberty in female European eels. This discrepancy has not yet been explained. High hydrostatic pressure also might be a triggering or stimulatory factor of sexual maturation in the Japanese eels. It would be worth trying in a future study to keep female eels under high hydrostatic pressure. In the present study, eels were kept in flow-through seawater tanks without feeding for 3 month. These environmental and physiological condition may affect to induce vitellogenesis in the female eel.

In conclusion, the present study indicates that long rearing in seawater increases responsiveness to salmon pituitary extract in ovarian maturation of the Japanese eel, resulting in shortened period from completion of oocyte growth. Morphological observation shows that gonadotrophs of the fish kept for 3 months in seawater become active and their oocytes attain at the primary yolk globule stage. These results indicate that an increase of responsiveness to salmon pituitary extracts is caused by use of vitellogenic eels in the present study. A shortened period for completion of oocyte growth reduces the consumption of salmon pituitary powder and labor required. Further studies are necessary for clarifying what kind of environmental condition are required for the completion of vitellogenesis and oocyte maturation.

Acknowledgments We would like to thank the director and staff of the Freshwater Resources Research Center, Aichi Fisheries Research Institute, Isshiki, Aichi Prefecture, for supplying the female eels. This study was supported in part by a grant-in-aid (Bio Media Program, BMP-97-II-2-5) from the Ministry of Agriculture, Forestry and Fisheries.

\section{References}

1) K. Tsukamoto: Discovery of the spawning area for Japanese eel. $\mathrm{Na}$ ture, 356, 789-791 (1992).

2) B. Querat, K. Nahoul, A. Hardy, Y.A. Fontaine, and J. LeloupHatey: Plasma concentrations of ovarian steroids in the freshwater European silver eel (Anguilla anguilla L.): effects of hypophysectomy and transfer to seawater. J. Endocr., 114, 289-294 (1987).

3) I. Boetius and J. Boetius: Studies in the European eel, Anguilla anguilla (L.). Experimental induction of the male sexual cycle, its relation to temperature and other factors. Meddelelser fra Danmarks Fiskeri-og Havundersogelser, 4, 339-405 (1967).

4) H. Kagawa, H. Tanaka, H. Ohta, K. Okuzawa, and K. Hirose: In vitro effects of $17 \alpha, 20 \beta$-dihydroxy-4-pregnen-3-one on final maturation of oocytes at various developmental stages in artificially matured Japanese eel, Anguilla japonica. Fisheries Sci., 61, 1012-1015 (1995).

5) H. Ohta, H. Kagawa, H. Tanaka, K. Okuzawa, and K. Hirose: Changes in fertilization and hatching rates with time after ovulation induced by 17,20 $\beta$-dihydroxy-4-pregnen-3-one in the Japanese eel, Anguilla japonica. Aquaculture, 139, 291-301 (1996).

6) H. Kagawa, H. Tanaka, H. Ohta, K. Okuzawa, and N. Iinuma: Induced ovulation by injection of 17,20 $\beta$-dihydroxy-4-pregnen-3-one in the artificially matured Japanese eel, with special reference to ovulation time. Fisheries Sci., 63, 365-367 (1997).

7) K. Yamamoto, M. Omori, and K. Yamauchi: Oogenesis of the Japanese eel. Nippon Suisan Gakkaishi, 40, 9-15 (1974).

8) H. Tachiki, T. Nakagawa, K. Tamura, and K. Hirose: Effects of oral administration of estradiol-17 $\beta$ to young on gonadal sex and growth of Japanese eel Anguilla japonica. Suisanzoshoku, 45, 6166 (1997).

9) K. Yamamoto, T. Morioka, O. Hiroi, and M. Omori: Artificial maturation of female Japanese eels by the injection of salmonid pituitary. Nippon Suisan Gakkaishi, 40, 1-7 (1974).

10) M. Yoshikawa: Relationships between gonadal maturity and body weight or age, and seasonal changes of them in cultivated Japanese eel Anguilla japonica. Bull. Shizuoka Pref. Fish. Exp. Stn., 30, 2327 (1995).

11) K. Yamamoto and $Y$. Nagahama: Cytological changes in the adenohypophysis of fresh-water cultivated male Japanese eels, Anguilla japonica, induced to maturation by transfer to seawater and Synahorin injection. Nippon Suisan Gakkaishi, 39, 585-594 (1973).

12) Y. A. Fontaine, S. Dufour, J. Alinat, J. Leloup-Hatley, and B. Querat: Deep sea immersion, gonadotropin, and sex steroids in the European eel (Anguilla anguilla L.). Gen. Comp. Endocrinol., 66, 27-28 (1987). 